\title{
Academic Reputation: How U.S. News \& World Report Survey Respondents Form Perceptions
}

Received (in revised form): April 18, 2003

\section{Phyllis V. Larsen}

is an assistant professor of advertising at the University of Nebraska-Lincoln's College of Journalism and Mass Communications. Prior to her faculty appointment, she was a public relations practitioner for two decades, serving most recently as Director of Public Relations for the University of Nebraska-Lincoln.

\begin{abstract}
One of the most widely read college rankings is published by U.S. Neres and World Report. The largest element of the ranking is a reputation score determined by a survey of higher education leaders. This pilot study explores how university presidents define academic reputation and form their perceptions for the USNWR ranking. Findings suggest that they create a set of factors to determine reputation, and that personal experience and interpersonal communication play significant roles.
\end{abstract}

\section{Keyzords:}

academic reputation, rankings, U.S. News and World Report, institutional image

\footnotetext{
Author's Contact Address:

Phyllis V. Larsen

Assistant Professor of Advertising

College of Journalism and Mass Communications

147 Andersen Hall

University of Nebraska-Lincoln

Lincoln, NE 68588-0449, USA

Tel: +1 4024728521

Fax: +1 4024724024

Email: plarsen1@unl.edu
}

\section{Introduction}

Each year, American institutions of higher education weather the criticisms or congratulations that follow the publication of an array of college rankings. One of the highest visibility rankings is U.S. Neres and World Report's (USNWR) "America's Best Colleges." Each September, this best-selling college guide is read by alumni, administrators, applicants, and nearly everyone interested in higher education.

While many in higher education question the validity of college rankings, the reality is that rankings do, indeed, have significant impact. In a study of top national universities and liberal arts colleges ranked by USNWR, Monks and Ehrenberg conclude that a move to a less favorable ranking leads an institution to accept a larger percentage of its applicants, while a smaller percentage enrolls. As a result, the entering class is of lower quality as measured by SAT scores.

Higher education marketing guru Robert Sevier considers reputation and image to be synonymous. Citing image as the most significant asset of an institution of higher education, Sevier's studies show that it is highly influential to prospective students. In 
surveys of thousands of high school students each year, four reasons for college choice emerge: image or reputation, location, cost, and availability of a specific major. When asked to prioritize their four reasons, students place image first.

Prospective students, parents, alumni, and higher education leaders focus on different qualities when determining college reputations because they have different agendas. In the USNWR ranking, reputation is determined by scores assigned to each institution based on votes from higher education leaders (HELs). As a result of the reputation score which strongly impacts the USNWR rankings with its 25 percent weighting, perceptions of this one public-higher education leaders-has the potential to exert significant influence on other publics.

Because reputation (as derived from HEL votes) is a critical factor in the college selection decision made by so many prospective students who read these rankings, it is important to understand how education leaders' opinions are developed. The goal of this exploratory study is to develop a hypothesis on how those who fill out USNWR's reputation survey form their perceptions of academic reputation-and how those perceptions may be influenced.

USNWR's first ranking took place in 1983 and measured only academic reputation. Over the years, the survey has been modified to reduce the weight of academic reputation to 25 percent. While six other ranking factors are now evaluated by USNWR, the factor of academic reputation continues to have the largest impact on the overall ranking. The reputation score is determined by results of a survey sent to presidents, provosts, and deans of admissions at institutions in similar classifications (national universities, for example). Survey respondents use a five-point scale to rate academic reputation, with one described as "marginal," two as "adequate," three as "good," four as "strong," and five as "distinguished." A “don't know” rating does not affect the overall score of an institution.

It is clear how data from the other six factors of financial resources, faculty resources, selectivity, retention, alumni giving, and graduation rate performance are developed, since each participating institution submits its data to USNWR. It is less clear, however, how the determination of academic reputation is made by survey respondents. Rapoport calls reputational scores a "dartboard approach" that is far from a reliable measure of quality.

\section{Purpose of the Study}

Various publics view higher education institutions differently depending on their context and perspective, causing institutions to have multiple images and reputations. Since USNWR bases each institution's reputation score solely on perceptions of higher education leaders such as university presidents and provosts, understanding how this particular public forms their perceptions has increased significance. Is there a method to their "dartboard approach"? This study serves as a pilot exploration of these research questions:

1. How does the public of HELs define academic reputation?

2. What factors influence HELs in their perception of an institution's academic reputation? 
3. How do these factors influence HELs' responses in the USNWR reputation survey?

4. How much credibility does the USNWR ranking have with HELs?

5. What sources and channels of communication do HELs use to gather information related to reputation of an institution?

\section{Literature Review}

The origin of reputation is found in providing public opportunities and in meeting public obligations as suggested by de Tocqueville in the nineteenth century. Today's scholars have identified a variety of factors contributing to reputation of higher education institutions including admissions selectivity, accomplishments of alumni, quality of faculty, size of endowment and operating budget, number of library holdings, peer rankings, and leadership quality.

A widely accepted yardstick of educational quality is based on intellectual productivity of an institution's faculty, including published research, citation counts of research, institutional patents, and grants. A review of reputational ranking studies concluded that undergraduate education reputation may be enhanced by increases in research activity.

Reputational rankings using peer assessment are another commonly used methodology. Subjective opinions of select groups of people-those considered to be in positions to know which are the highest-quality institutions-may have limited objectivity since many are asked to rank their alma maters.

Scholarly work in the area of academic reputations also includes examination of quality measurements in specific university or college departments. Garand and Graddy explored a controversial National Research Council study using publications in scholarly journals as a parameter for ranking quality of university and college political science departments. They concluded that while production of many low-impact publications appears to do little to enhance a department's reputation, departments whose faculty publish in the highest-impact political science journals have considerably stronger subjective reputations. These findings suggest that it is the quality, not the quantity, of publications that impact a department's reputation.

While Keith and Babchuk acknowledge the body of research demonstrating strong ties between departmental prestige and the levels of its faculty scholarship, their own study concludes that scholarship is less important in determining prestige ratings than past reputations of universities.

This 'institutional halo effect' was also seen in research showing that categorization as a Carnegie research university and undergraduate selectivity was a significant factor in whether or not the quality of program faculty was highly rated.

While historical legacy, prevailing opinions, and rankings influence institutional reputations, Theus's study of higher education officials showed that interpersonal communication as well as mass-mediated communication play a more significant role in forming perceptions of reputation. Published rankings and institutional literature were put at the bottom rung of potential influence.

\section{Methodology}

This exploratory pilot study was part of a wider study conducted for a public research university (University $\mathrm{X}$ ). While 
the goals of the institutional study included assessment of perceptions of University X's academic reputation, this paper will focus on formation of academic reputation as it relates to all institutions being considered by USNWR survey voters in the study's sample.

This qualitative study used depth interviews of 15 leaders of 12 different public research universities in 12 states. With the exception of two provosts, the respondents were all presidents or chancellors primarily at the campus level of administration, although one system president was included. Six were leaders of land-grant institutions with Association of American University membership. The other nine were from institutions not having land-grant or AAU status.

Purposive convenience sampling was used. Participants agreed to be part of the study after receiving a letter inviting their involvement. The invitation was signed by the chancellor of University $\mathrm{X}$ with the hopes of getting through gatekeepers who protect administrator's schedules. This chancellor had a strong interest in the formation of academic reputation, as did the 15 who responded to the incentive of receiving a summary of findings at the completion of the study.

Thirty-four letters were sent to presidents or chancellors of institutions with similarities to University X. Because USNWR reputation survey respondents vote only in their own institution's category (national universities, for example), the researcher wanted opinions of those actually voting in the same category as University $\mathrm{X}$ in order to assess its current reputation. Respondents were recruited from the membership of the Kellogg Commission (an organization created in 1996 by the National
Association of State Universities and Land Grant Colleges to help define the future direction of public universities) and from leaders of University X's athletic peer group. These populations were targeted because (a) they were seen as leaders with significant influence in and understanding of higher education, and (b) they represented institutions with some characteristics similar to University X.

The letter of invitation to participate in this study read, in part:

University X's marketing team is studying the formation of institutional academic reputations among higher education opinion leaders, particularly those who rate institutions in the annual survey for U.S. Newes and World Report ... While we are interested in individuals' perceptions of the academic reputation of University $\mathrm{X}$, our primary focus is much broader, i.e., how they define academic reputation, how they form their opinions about academic reputation, their sources of information about academic reputation, etc.

Most of the interviews were conducted via telephone with the exception of two interviews which were conducted face-toface and one which was done in writing. Telephone interviews allowed access to participants in a wide geographic area. Interviews ranged from 60 to 90 minutes in length. Because some participants preferred not to have interviews taperecorded, telephone interviews were conducted using a speakerphone so that both the interviewer and a transcriber could hear responses.

Interviews were structured, with each participant being asked the same questions. Screening questions were asked 
to assure that the appropriate person was being interviewed-a president or provost who had personally filled out the USNWR survey in the past. In addition to the structured research questions, the interviewer probed for additional information. Interview questions included:

1. How do you define academic reputation?

2. What factors do you consider in assessing other institutions reputations? Which are the most important factors?

3. How would you describe the importance of USNWR's college rankings? (Probe for opinion on validity if not mentioned).

4. This year, the USNWR survey asked about academic reputation in terms of each institution's scholarship record, curriculum, and quality of faculty and graduates. Did you use any other information in your ratings? Please explain.

5. How do you learn about (the information they mention) at different institutions? What are your sources of information? (Probe the following areas)

a. What role does personal interaction or experience with other institutions play?

b. What role does mass media play? (ask for specifics on publications mentioned, advertising, etc.)

c. What role does information sent to you from the other institutions play?

\section{Findings}

\section{Academic reputation definition}

Academic reputation was generally defined by these higher education leaders as the overall impression of excellence or quality created by a number of factors. Eight factor categories were developed by matching frequently used word groups from interview transcripts with key areas from other studies. Quotes from respondents follow each factor description.

\section{Factors used to define academic reputation}

\section{Faculty quality (members in National Academy of Sciences; Guggenheim, Fulbright, Nobel Prize winners; publishing success; national reputation as a star in their discipline)}

I have a preference in ranking toward institutions that have a quality facultythose that demonstrate innovation and have strong academic programs.

I use a data set of achievements and faculty recognition such as Fulbrights, Guggenheims, National Academy memberships, number of grad programs in the top 20 NRC rankings, NSF fellowships over the last five years, and library quality.

\section{Credible rankings (Association of American Universities, National Research Council rankings)}

Reputation also depends on the degree to which an institution shows up in a loose constellation of markers such as AAU, National Academy of Sciences, major grants received, and so on.

Resources (federal and state funding, grants, research and development expenditures, private support)

Resources help determine reputation. Schools that are better supported or 
endowed and get more research funding are usually those with strong reputations.

My opinion of University $\mathrm{X}$ has changed in the last five to eight years because the financial funding data has shown significant progress.

\section{Research strength (National Science} Foundation felloweships, overall research reputation, quality of graduate programs)

Many perceive research achievement and major discoveries that get connected to an institution as a component of academic reputation.

I consider research productivity (in determining reputations)-NSF programs, increased efforts in math and science.

\section{Student quality (ACT scores, admission} selectivity, graduation rates)

Selectivity is important. Privates will always have a leg up on reputational rankings because of it. You can't unseat Harvard and Princeton from the top 25.

\section{Leadership strength (visibility of chancellor or president on significant national issues)}

When very solid people are leading the institution, you think highly of the institution.

The president's visibility and participation nationally is key.

I've changed opinions of other institutions, especially after interacting a lot with the president. Leadership does make a difference.

\section{Historic reputation or general perceptions} (tradition, word of mouth)

I have a nonscientific, qualitative method of ranking. It's somewhat anecdotal and fuzzy.

I think many people have an overreliance on historical impressions. Those founded long ago, like Ivy leagues, have great luster. We're slow in according newcomers the reputation they deserve. We also hold institutions in high esteem that have faded.

\section{Program quality (balo effect from individual program strengths)}

No institution is strong in every single area, but public perception transfers program strength into institution-wide reputation.

In addition to defining academic reputation, many respondents mentioned that reputation is established slowly and is difficult to change. Public perception may often lag behind reality. One respondent said, "Reputation is based on long-term history. It's hard to change. Marketing can't change most of the things that really influence academic reputation. For example, it takes serious resources to get top faculty to come and stay."

\section{Perceived importance of $U S N W R$ rankings}

Most respondents expressed skepticism about the validity of USNWR rankings. 'When you're ranked well, you tend to brag about it. When it's not so good, you discount it. Everyone does that and everyone has doubts about the validity of the U.S. Newes and World Report rankings," a respondent said. 
Although rankings lack credibility with higher education leaders, many recognize that prospective students and other publics do give rankings consideration and therefore, cannot be completely ignored. "I don't give (USNWR) much credibility, but I recognize that lay people do, so I believe we must pay attention to the ranking," a respondent said.

While most of those interviewed downplayed the significance of the ranking, most respondents filled out the reputation survey instrument themselves, year after year. They completed the survey only for institutions with which they had a high or moderate level of familiarity, estimating completion rates of 40-90 percent.

\section{Information used in responding to the $U S N W R$ reputation survey}

Although USNWR specifies its definition of academic reputation in the reputation study instrument, respondents agreed that they applied their own personal definition, as described in the factors above, when completing the USNWR survey. The survey asks voters to rate the "academic quality of undergraduate programs" at each institution while considering "scholarship record, curriculum, and quality of faculty and undergraduates." Respondents agreed that they used additional information when assigning reputation scores to other institutions and that gauging quality and curriculum of undergraduate programs was difficult. "I can't consider matters of curriculum as asked by the survey. I can't access that information nationwide. I have no idea of curriculum even in nearby institutions," a respondent said.

The primary theme of this additional information used to respond to the survey was general perceptions and specific knowledge gained through personal experience with the institution and personal contact with other presidents, including participation on program review teams or in national leadership organizations. One respondent said, "My impressions are largely based on what I know or learn from individuals at the institution-more often than not the administration, not the faculty." Another said, "I use personal experience to determine academic reputation-35 years of contact with other institutions and their leaders through meetings with AAU, $\mathrm{NIH}$, NASA, campus visits, and my own research discipline specific activities."

While respondents acknowledged some value in personal interaction with their peers, one said, "My perceptions are somewhat dependent upon those I have interaction with. However, I don't put too much stock in what presidents and provosts say. (laughs) Sometimes they lie."

A strong secondary theme of information used to respond to the USNWR survey was perceived strength of institutional leadership through visibility of the president on significant national issues; quantitative data such as National Research Council rankings, research funding, AAU membership, and number of National Academy of Sciences faculty members; anecdotal data and "personal judgment"; and evidence of innovation, diversity, and best practices.

A less prevalent theme was raiding of faculty from other institutions, creating a perception of the hiring institution being "on the move." "Knowledge that two or three top people in a field have been hired by the same institution-that gets noticed," a respondent said. Success of graduates, size of the endowment, graduate program 
quality, and value-added components such as community service were also tertiary themes.

\section{Sources of information on academic reputation}

In considering sources and channels of information used to form perceptions of academic reputation, respondents in this study reinforced several of the findings of Theus's 1993 study. HELs view institutional reputations as being strongly influenced by communications, particularly the consistency and pervasiveness of interpersonal messages, and by high credibility mass-mediated messages.

Three points were reinforced by each respondent in this study. First, personal contact is highly influential. HELs formed opinions of an institution based on their own experience with a university. Personal interaction with a university's leadership is also highly influential. These interpersonal communications may take place in the context of mutual membership in national organizations or academic review teams. For some respondents, interpersonal communication had more influence than other qualitative data. "Academic leaders are a more credible source of information than glossy magazines," a respondent said.

The second point mentioned by all respondents was that institutional literature may raise awareness in other publics, but is not highly influential with the HELs. Respondents said they don't read annual reports or promotional brochures that cross their desk. Publications that focus on the president's specific field of interest are occasionally read by this audience.

"University-produced publications are not very meaningful to me. I pass those sorts of publications to my public relations people," a respondent said. Another said, "(Institutional publications) only influence those who don't know the guts of the institution. They don't influence their rating of different universities in U.S. Neres."

The third point made consistently was that mass-mediated communication may provide information and influence if it is perceived to be from unbiased sources such as national news or industry specific publications. All HELs mentioned reading the Chronicle of Higher Education and several mentioned reading Science and Change magazines, or other more specialized periodicals in the academic discipline of the reader. "I pay more attention to articles in higher education publications than the popular press," a respondent said. Another said, "I read the Chronicle of Higher Education for news content, but I choose a limited number of articles to read on higher education issues. I do much of it on-line."

Unless articles are closely read or include data especially related to funding, mass media publications were not perceived to have a large impact. News articles are perceived as being more credible than paid advertising. While much of the research in the field of advertising supports its ability to influence, respondents of this study disagreed. Many of those interviewed believe advertising in almost any form had no effect or a negative effect, except if it announced an innovative program. Advertising with a pure image message had no effect or a negative effect, according to respondents. "I don't typically read advertising. I'm not influenced by image ads. I do, however, like information on new programs (in ads)," one respondent said. 


\section{Discussion}

Consider the relationships explored in this study: high school students rate reputation as one of the most important factors in their college choice decision; reputation scores carry the heaviest weighting in the widely read USNWR rankings; those reputation scores are determined by college presidents, provosts, and deans of admissions. For those admissions and public relations professionals considering how to influence prospective students, the impact of higher education leader's opinions cannot be ignored.

HEL respondents in this study showed that when completing the USNWR reputation survey, they do not consider the same factors as specified on the survey instructions. Rather, they employ an individualized set of factors when developing perceptions about academic reputation. Themes that emerged showed that they value and learn from personal experience and interaction, especially with their HEL peers. They also place a low value on institutional literature's ability to influence and confer credibility to a narrow range of mass media.

\section{Limitations of the study}

Limitations of this study must be considered. Because this exploratory pilot study had a small homogenous sample, findings cannot be generalized to the entire population, nor can findings be applied to other types of educational institutions. This study does, however, suggest hypotheses and research questions for further research. A broader study including leaders from public liberal arts institutions or four-year state colleges, for example, would determine whether HEL opinions are consistent among diverse institution types. An additional set of questions of specific interest to the higher education public relations practitioner may also be helpful. Did any of these HELs consciously work to influence their peers' perception of their institution's academic reputation? If so, what methods were used? How successful were their efforts?

Building a significant sample for this study was challenging due to the difficulty of securing 90 minutes in the schedule of presidents and chancellors for someone unknown to them. Many respondents expressed interest in the incentive of receiving summary data, indicating they would make time in their schedules for that reason alone. However, it is possible that some who responded may have done so due to an existing relationship with the researcher's chancellor, introducing the opportunity for bias.

Using consistent methods for collecting information would have been preferred. However, rather than have a smaller sample, the decision was made to complete the three interviews where the face-to-face and written methods were requested by the participants.

\section{Observations for Practitioners}

While university relations work involves many publics, communication with leaders of higher education must be carefully considered. Overlooking the significance of this audience means overlooking the profound effects they may have on how students select a college. Failing to plan communication strategies for HELs leaves it to chance that they will develop an accurate perception of the universities they rate in USNWR's reputation survey.

Public relations professionals who do, indeed, plan their communication with HELs should evaluate their strategy to 
determine if traditional methods are effective. For example, spending significant resources distributing annual reports or purchasing advertising aimed at influencing HEL voters prior to receiving USNWR's survey each spring may not be have the intended results. Many participants in this study remarked that the slick publications sent to them by other institutions do not influence them positively, and can cause perceptions of a university "trying too hard" to boost reputation.

It appears that relationship building, creating opportunities for first-hand experience, and interpersonal interaction with presidential colleagues, promises significant impact in influencing higher education leaders' perceptions of institutional reputation. This approach is more consistent with a two-way, symmetrical communication model recommended as the normative model for public relations and may prove to be more effective in communicating the true academic reputation of higher education institutions. Using the list of factors defining academic reputation as talking points for institutional leaders interacting with their peers may enhance their ability to inform others of areas relevant to academic reputation.

Faculty quality, credible rankings, resources, research strength, student quality, leadership strength, historic reputation, and program quality are all considered by those voting on USNWR's reputation survey. Strengthening these areas as well as effective communication with HEL peers is key. Not only do higher education leaders influence each other, their opinions reach mass audiences of prospective students who are, indeed, influenced by rankings.

\section{References}

1. N. Thompson (2000), "Playing with numbers," Washington Monthly, 32, September, p.16.

2. J. Monks and R. G. Ehrenberg (1999), “U.S. Nezes \& World Report's college rankings: Why do they matter?" Change, November/December, pp. 43-51.

3. R. A. Sevier (1994), "Image is everything," College and University, 69, Winter, pp. 60-75.

4. P. Cary and R. J. Morse (2000), "College rankings: Do alumni matter?" Presentation at the Council for Advancement and Support of Education District VI Conference, St. Louis, MO, January.

5. N. B. Rapoport (1999), "Ratings, not rankings: Why U.S. Newes \& World Report shouldn't want to be compared to Time and Newerweek-or the New Yorker," Ohio State Law Journal, 60, 3, pp. 1097-1101.

6. Sevier (1994), "Image is everything," op. cit.

7. K. T. Theus (1993), "Academic reputations: The process of formation and decay," Public Relations Review, 19, Fall, pp. 277-91.

8. L. C. Hattendorf (1996), "Educational rankings of higher education: Fact or fiction?" Paper presented at the International Conference on Assessing Quality in Higher Education, Queensland, Australia, July.

9. S. Grunig (1997), "Research, reputation, and resources: The effect of research activity on perceptions of undergraduate education and institutional resource acquisition," Journal of Higher Education, 68, 1, pp. 17-52.

10. Hattendorf (1996), "Educational rankings of higher education,” op. cit.

11. J. C. Garand and K. L. Graddy (1999), "Ranking political science departments: Do publications matter?" Political Science o Politics, 32, 1, pp. 113-17.

12. B. Keith and N. Babchuck (1998), "The quest for institutional recognition: A longitudinal analysis of scholarly productivity and academic prestige among sociology departments," Social Forces, 76, 4, pp.14951534.

13. J. S. Fairweather (1988), "Reputational quality of academic programs: The institutional halo," Research in Higher Education, 28, 4, pp. 345-55.

14. Theus (1993), “Academic reputations," op. cit.

15. Ibid.

16. J. E. Grunig and L. A. Grunig (1992), "Models of public relations and communication," in J. E. Grunig (Ed.), Excellence in Public Relations and Communication Management, Erlbaum, Hillsdale, NJ, pp. 285-325. 


\section{Practitioner's Perspective}

The freshness and clarity of Professor Larsen's research is the result not only of its simplicity and overall focus but also of her very own lucid self-restraint. What erudite social scientist, provocative journalist, or hard-driving "higher education leader" can utter the letters USNWR without an almost apoplectic urge to persuade his or her audience of the intellectual quirks of these, our most well publicized, universally read, and often overemphasized college rankings? Professor Larsen accepts $U$. S. Newes and World Report rankings as a fact of academic and journalistic life, helping "higher education leaders" (HELs) and their deputies to more fully understand the pitfalls and process of the all-too-weighty "reputation" score, roundly criticized for 20 years now by policy makers and practitioners alike.

Larsen's interviews of 15 HELs at 12 public institutions remind her readers of the "dartboard approach" taken by many survey respondents, who may at times forget just how dramatic a 25 percent weighting can be when the remaining 15 ranking criteria range in "weight" from 1 to 16 percent. Larsen's focus on the reputation score is appropriate and only suggests the need for further investigation.

The goal of this self-described "exploratory" study is to "develop a hypothesis on how those who fill out USNWR's reputation survey form their perceptions and how those perceptions may be influenced." In her interviews, Larsen finds that HELs consider eight factor categories: (1) faculty quality, (2) (so called) credible rankings, (3) resources, (4) research strength, (5) student quality, (6) leadership strength, (7) historic reputation, (8) program quality. Although USNWR provides a specific definition of "reputation," many HELs admit that they apply their own personal definitions. All respondents point out that personal contact with colleague HELs is "highly influential"; mass-mediated communication may be influential if perceived as coming from an objective source, and institutional literature is seen as having little effect.

Though Professor Larsen's small sample is an obvious limitation of the study, public relations professionals, enrollment managers, and advancement officers would do well to note her suggestions to rely less on annual reports and more on interpersonal communication, shaping "talking points" for their presidents around the eight factors mentioned above. In the final analysis, those of us who fill out U. S. Neres's annual surveys would do well to study Professor Larsen's findings and consider for ourselves more objective personal standards for measuring "reputation," while advocating for more meaningful measures of an institution's quality, such as student satisfaction, financial strength as determined by external agencies, and the richness of campus technology. Until such time as the weight of this most subjective measure-reputation-is reduced or more objective criteria for its determination are embraced, I will continue to elicit wonderfully positive responses to the always challenging question, "How good is the Princeton Law School?" 